\title{
EXPERIÊNCIA DE ENVELHECIMENTO: TRABALHO E APOSENTADORIA
}

\author{
Giseli Gontarski ${ }^{1}$ e José Miguel Rasia ${ }^{2}$
}

\begin{abstract}
RESUMO
Esta pesquisa tem como objetivo principal compreender a experiência de envelhecimento de doze homens e mulheres, com idades entre 68 e 95 anos, moradores da cidade de Mafra-SC. 0 trabalho e a aposentadoria foram fundamentais na construção dos significados da velhice. A pesquisa demonstrou que existem diversas formas de envelhecer, tanto positivas, quanto negativas. Além disso, há uma grande distância entre os discursos elaborados sobre 0 envelhecimento e a forma como os entrevistados efetivamente experimentam essa etapa da vida. Nesse momento, não é a velhice sinônimo de perda e decadência que está sendo mencionada e sim uma outra velhice, bem mais positiva, que considera sobretudo as trajetórias individuais.
\end{abstract}

Palavras-chave: Velhice. Experiência. Doença. Trabalho.

\section{AGING EXPERIENCE: JOB AND RETIREMENT}

\section{ABSTRACT}

This research has been main goal to understand the aging experience of twelve men and women, between 68 and 95 years old, they live in Mafra- SC. Their job and retirement were central in meaning construction of aging. Research proves to have several manners of old, so positives as negatives. Besides, there is a great difference between the theory about the aging and the manner how this persons live though this stage of their life, this time isn't the old synonymous with loss and decline that it talking about, but another aging, more positive, especially considering the individual trajectories.

Keywords: Elderly. Experience. Illness. Job.

\footnotetext{
${ }^{1}$ Mestre em Sociologia pela Universidade Federal de Paraná, Brasil. giseligontarski@yahoo.com.br

${ }^{2}$ Professor Titular de Sociologia e do Programa de Pós-Graduação em Sociologia, Universidade Federal de Paraná, Brasil. zecarasia@gmail.com
} 


\section{INTRODUÇÃO}

$\mathrm{H}$

á algumas décadas o Brasil tem vivenciado o fenômeno do envelhecimento e com isso buscado formas de garantir o lugar desses "novos" sujeitos sociais. As lentes

que observam a velhice são as mais variadas possíveis, identificando-a como 0 tempo da decadência e/ou da liberdade, da restrição e/ou do desfrute, ambiguidade essa que está presente inclusive nos discursos dos velhos quando falam de si. A velhice é uma experiência plural, o que faz com que os sentidos atribuídos ao envelhecimento sejam os mais variados possíveis. Essa pesquisa trabalha a velhice sob a perspectiva das Ciências Sociais, que a compreende como uma construção social, o que significa que cada cultura, cada tempo histórico cria um sistema simbólico próprio para representar o velho. Além disso, o envelhecimento é também uma construção subjetiva que varia de acordo com as trajetórias particulares de cada sujeito. E é também por considerar a velhice como uma experiência social que utilizamos o termo velho para nos referirmos a esses sujeitos, tentando justamente desconstruir a imagem pejorativa incorporada por esse termo em nossa sociedade.

A pesquisa de campo, que utilizou a técnica da entrevista semiestruturada, foi realizada com doze homens e mulheres com idades entre 68 e 95 anos, na cidade de Mafra, interior de Santa Catarina. A maior parte dos entrevistados são católicos, nasceram e foram criados em comunidades rurais, são ou foram casados, tiveram filhos, tem uma escolaridade baixa, são aposentados e possuem uma renda mensal em torno de dois salários mínimos.

\section{TRABALHO E APOSENTADORIA}

As narrativas dos velhos pesquisados estão marcadas por inúmeros eventos sobre um tempo experimentado e marcado, tanto na memória quanto nos seus corpos. Todos esses eventos contribuem para os sentidos elaborados sobre a velhice, mas dois deles foram essenciais nessa construção: Trabalho e aposentadoria. Entender o sentido dessas experiências sociais para os velhos significa perceber a própria compreensão que eles têm da velhice, que aparece de variadas formas, considerando a singularidade de cada trajetória e o papel da subjetividade na construção do envelhecimento.

Ao longo da pesquisa de campo, percebemos que as histórias mais recorrentes foram aquelas ligadas às experiências que mediavam a relação entre 0 indivíduo e 0 trabalho. Essas histórias dizem muito sobre quem são os velhos pesquisados e o que eles pensam sobre si.

Apesar de atualmente a maioria dos entrevistados viver na cidade - dez deles -, todos têm uma origem rural, na agricultura familiar, cresceram trabalhando na lavoura. Nesse contexto, o trabalho é sinônimo de virtude. Desenvolvido como ajuda 
mútua em prol dos membros da família e da manutenção da propriedade rural, de tal modo que parar de trabalhar pode significar a perda da dignidade do indivíduo. Para esse grupo, a essência sobre o papel do homem no mundo está no trabalho e nesse sentido, quando não pode trabalhar, é como se o indivíduo não estivesse completo, como se perdesse a identidade.

Essa justificativa está implícita no discurso de Ezequiel, que com 83 anos, faz questão de manter uma pequena lavoura nos fundos de casa e trabalhar nela todas as manhãs. Além disso, ao longo de toda a entrevista, Ezequiel fez questão de explicitar a realização que sente pelo que conquistou através do trabalho:

o que tem de bom é que, Graças a Deus, nos tamo no que é nosso! Porque nos trabalhemo em escola. Morava na escola [a mulher dele era professora] e trabalhava na roça. Daí de lá vim aqui pra cidade. Eu vim por causa da familia como eu te contei, então aqui eu comprei esse terreno, e fui construindo. Vim morar aqui no centro da cidade, um ano, ficamos lá e nesse um ano eu ia pro interior trabalhar, e dai fiz aqui pra mim. Então, graças a Deus, nos tamo no que é nosso mesmo, tamo tranquilo. Tudo essa parte aqui [aponta a dimensão do terreno]... Porque no começo eu tava no aluguel. O que teve de bom foi construir o futuro (Ezequiel, 83 anos).

Mais do que fonte de renda, o trabalho pode ser entendido como o elemento que possibilita ao homem registrar sua história, seja através dos bens adquiridos ou do legado deixado aos filhos e netos sobre a trajetória de uma vida toda de trabalho. É trabalhando que Ezequiel conserva seu lugar na sociedade.

Mas nos últimos anos ele tem enfrentado um confronto entre o desejo de trabalhar e os limites físicos impostos pelo corpo, que já não é mesmo de antigamente: 0 novo tem que fazer enquanto ta novo, porque quando chega numa certa idade, ele quer fazer, mas não pode (Ezequiel, 83 anos). Ezequiel conta que sente muita dor nas costas, pernas e pés, mas mesmo assim não pretende parar de trabalhar na sua roça. $\mathrm{Na}$ visão de Ezequiel, continuar a trabalhar, mesmo sentindo dor, foi a forma que encontrou de garantir sua humanidade, de "manter seu corpo na história" (DELGADO, 2010) e provar que é capaz de continuar desempenhando seu papel. Diante do sentido que ele construiu sobre o trabalho, a dor pode ser tolerada.

A narrativa de Estela, que trabalhou a vida toda na roça, traz uma compreensão semelhante sobre 0 trabalho. Aliás, o significado elaborado sobre sua velhice está extremamente alicerçado na imagem que ela tem do trabalho. Este constitui a forma pela qual a vida toma sentido e um dos meios pelo qual o indivíduo cumpre seu papel no mundo. Na narrativa de Estela sobre o trabalho, mesmo que aponte esforço e 
dificuldades na sua realização, ele aparece como uma prática prazerosa, uma virtude que a acompanhou até a velhice:

Assim eu gosto... gostava de trabalhar. Mas agora eu não consigo. Assim a calçada, eu passo a vassoura. Pra movimentar, isso que eu gosto. E às vez lavo louça. Varro a cozinha (Estela, 95 anos).

0 que a entristece é que ultimamente não tem mais conseguido trabalhar. Ela conta que sempre pensou que quando não pudesse mais trabalhar iria descansar, pois a velhice deveria ser um tempo de recompensas e de descanso para quem trabalhou muito na juventude. Essa compreensão concede à velhice uma imagem positiva, entendida como um período da vida sem sofrimentos em que o sujeito pode descansar ou trabalhar apenas por gosto.

Mas, o que angustia Estela é que esta é apenas uma imagem idealizada da velhice ou como ela deveria ser, uma vez que sua experiência de envelhecimento acabou tomando outra direção e seus ideais de velhice não se concretizaram. Estela se queixa que hoje, aos 95 anos, mesmo morando com a filha e o genro tem uma vida completamente solitária, excluída das conversas, dos passeios e até mesmo dos acontecimentos que envolvem a família. Além disso, ela enxerga muito pouco e caminha com dificuldade, o que compromete sua autonomia fazendo com que permaneça "presa" em casa. Toda essa situação leva Estela a questionar sua permanência nesse mundo: tanta gente nova morre, e os velho ficam, sofrendo... Por que sofrer se trabalhou tanto? (Estela, 95 anos). Nas entrelinhas de sua fala é possivel perceber que a partir do momento em que parou de trabalhar, por causa da pouca visão e da falta de mobilidade trazidas pela velhice, a vida mudou. Estela perdeu seu lugar no mundo e foi jogada à margem dele.

Sebastião cresceu na roça, mas buscou na cidade melhores condições de emprego e de vida. Trabalhou como pedreiro e mestre de obras numa construtora e depois de aposentado, por conta própria. Só parou mesmo de trabalhar fora depois que descobriu um enfisema pulmonar. O médico proibiu eu até de cortar grama, por causa de fumaça e pó. Porque eu tenho problema de efisema pulmonar (Sebastião, 83 anos). Mas apesar das recomendações médicas, Sebastião afirma, quase em tom de confissão, que em casa ainda continua trabalhando:

Pois eu, pra falar a verdade, ando pra lá, ando pra cá, arranco um mato, essas coisas... Viro terra, carpo, corto a grama, trato os passarinhos. Porque parar de vez, não consegue parar, jamais! Trabalhar desde criança até agora... e não poder mais? (Sebastião, 83 anos). 
Podemos pensar que é muito difícil para Sebastião parar de trabalhar, pois o trabalho tem o papel fundamental de inseri-lo no mundo e de transformá-lo em sujeito - homem, pai de família, mestre de obras. Como Sebastião poderia deixar de trabalhar se desde criança foi isso que fez, se é esta a condição que o faz sentir-se socialmente integrado?

Diante desse significado do trabalho apresentado pelos velhos entrevistados é possível afirmar que a continuidade do trabalho na velhice representa a luta para provar à sociedade seu lugar e marcar sua presença. É pelo trabalho que o velho prova aos outros e a si mesmo que 0 avanço da idade não retirou seu lugar no mundo, que continua vivo e atuante. Seu Ezequiel afirma: o médico mesmo me falou: você tem acido úrico ou reumatismo. Mas eu, graças a Deus, vivo bem, porque de manhã cedo eu trabalho (Ezequiel, 83 anos). Esse trecho demonstra que a continuidade do trabalho foi a forma que Ezequiel encontrou de preservar sua identidade. 0 trabalho aqui é condição objetiva para que ele viva e reconstrua diariamente sua subjetividade. Mas qual será o destino de Ezequiel e Sebastião se eles não puderem mais trabalhar? Será a mesma marginalização a que se refere Estela?

As falas de Ezequiel, Estela e Sebastião mostraram que o trabalho está ligado a virtude, a força e a luta. Mais que o sustento da família, ele garante social e subjetivamente a manutenção da identidade do sujeito e não só do trabalhador. Sendo assim, sua ruptura instaura nos entrevistados o sentimento de que perderam a importância e a legitimidade de habitar esse mundo.

Diante desse sentido atribuído ao trabalho, qual seria o papel da aposentadoria na vida dos velhos? A aposentadoria é um tema muito presente na literatura sobre envelhecimento. A aposentadoria, assim como a velhice, foi olhada por diversos ângulos e distintos também podem ser pensados os significados desse acontecimento para 0 trabalhador.

Segundo Bosi (1994), mais que perder o papel de trabalhador, o aposentado fica destituído de sua própria humanidade. Nessa perspectiva, desenvolvida na década de 1970, a aposentadoria aparece como o evento que pode destituir o velho de seu papel social - pois o trabalhador passa a ser velho. No estudo em que reconstitui as memórias de velhos trabalhadores urbanos, na cidade de São Paulo, Bosi critica o lugar reservado aos velhos nas sociedades capitalistas:

Sobre a inadaptação dos velhos, conviria meditar que nossas faculdades, para continuarem vivas, dependem de nossa atenção à vida, do nosso interesse pelas coisas, enfim, depende de um projeto. De que projeto o velho participa agora? [...] se o trabalhador aposentado se desespera com a falta de sentido da vida presente, é porque em todo o tempo o sentido de sua vida lhe foi roubado (BOSI, 1994, p. 80). 
Segundo ela, a responsabilidade pela maneira como a velhice é tratada nas sociedades contemporâneas, ou seja, como problema, é da estrutura imposta pelo capitalismo que não oferece condições para que os indivíduos se estabeleçam como homens. E qual seria a solução para que a identidade não fosse roubada na velhice? Para Bosi "a resposta é radical...: seria preciso que ele sempre tivesse sido tratado como um homem" (BOSI, 1994, p. 81). Por que a sociedade capitalista não nega lugar somente aos velhos, mas aos trabalhadores de qualquer idade. Sob esse olhar, a aposentadoria demarca a passagem da maturidade para a velhice, num movimento que retira os indivíduos do espaço público levando-os de volta ao mundo privado da casa.

Entretanto, os mesmos autores que atentam para o papel mais negativo da aposentadoria, lembram que ela pode ter outros significados, bem mais positivos. Para Delgado (2010, p. 201), a aposentadoria inaugura uma reflexão sobre a velhice, sobre 0 sentimento do corpo velho e principalmente sobre os lugares que a velhice destina à vida. Uma reflexão que preserva a imagem do trabalhador.

Essa visão mais otimista em relação à aposentadoria também foi encontrada nos estudos que tratam do sentido do trabalho e da aposentadoria no mundo rural nas pesquisas de Sugamosto (2003) e de Heck \& Langdon (2002). Segundo Sugamosto, que trabalhou com agricultores familiares de Colombo-PR, a

aposentadoria não significa o afastamento do mundo do trabalho e não é sinônimo de velhice, mas de direito e possiblidade de melhorar o orçamento doméstico (SUGAMOSTO, 2003, p. 100).

$\mathrm{Na}$ agricultura familiar, aposentar-se geralmente não significa parar de trabalhar, mas a possibilidade de aumentar a renda da família. A diminuição do trabalho ou o afastamento total dele, entendidos nesse contexto como situações que demarcam o envelhecimento, só acontece quando os trabalhadores passam por uma experiência de adoecimento.

Situação semelhante foi encontrada em nossa pesquisa sobre as experiências de velhice, realizada com os idosos de Mafra-SC, tanto para trabalhadores urbanos como trabalhadores rurais. No conjunto dessas narrativas, 0 aposentado como inativo e decadente não foi uma imagem presente. A maior parte das experiências, sobretudo a das mulheres, sugere um sentido bem mais positivo sobre a aposentadoria.

Do universo de doze entrevistados, apenas Dolores não é aposentada. Mesmo tendo trabalhado muitos anos na roça, ela não teve como comprovar ao INSS esse vínculo porque não tinha terreno em seu nome. Dentre os que recebem o benefício, quatro aposentaram-se pela agricultura: Ana, Estela, Carmem e Ezequiel. Maristela e 
Vitória se aposentaram como professoras, Sebastião como pedreiro e Lourdes como artesã. Joaquim e Olívia, mesmo tendo direito ao benefício pela agricultura, preferiram contribuir com a previdência como trabalhadores autônomos, pois "não confiavam" na aposentadoria rural. Euclides, que trabalhou na indústria e no comércio, foi aposentado por invalidez, depois de duas fraturas na perna. Em relação aos valores das aposentadorias, eles variam entre um e pouco mais de dois salários mínimos.

As experiências de aposentadoria registram desde o descontentamento em relação ao baixo valor do benefício como também a sua relevância na melhora da qualidade de vida do trabalhador. Joaquim conta que:

Eu contribuía sobre um salário, dai eu queria fazer um alvará, como de aluguel, que eu comprei uma caminhonete. Fui no INPS3, perguntei se eu podia contribuir agora pra dois salários. Dai ela disse que tinba que contribuir agora mais um ano, pra depois subir. Dai eu disse pra ela: Então veja aí no computador quantos anos eu tenho de contribuição. Ai deu 34 anos, 9 meses e 11 dias de contribuição, se quer se aposentar já, é um salário. E foi o que eu fiz (Joaquim, 74 anos).

Ele sabe exatamente os anos, meses e dias que contribuiu com a previdência social. Diz ainda que o governo não agiu certo, como por exemplo, na aposentadoria da esposa, que contribuía com dois e depois três salários e hoje recebe apenas um salário mínimo.

Então o salário dela [da esposa] vai quase todo, quatrocentos reais, pra comprar remédio. O meu vai uns cento e cinquenta, cento e sessenta. Então com mil e poucos reais não dá nada, pagar água, luz, telefone, $e$ tudo... Então nos temos umas outras reservas (Joaquim, 74 anos).

Joaquim reclama que só com o salário da aposentadoria não dá para viver, pois grande parte é destinada aos remédios - usa dois medicamentos para a pressão e outro para a tireoide - e que se não fossem os bens que conseguiu adquirir durante a vida, estaria passando necessidade.

Para Ezequiel (agricultor), a reclamação não é em relação ao valor da aposentadoria, mas o tempo que levou pra conquistá-la:

Meus filho aqui tão aposentado mais novo do que eu! Do que ela também! Aquele tempo lá, tinha que ter 65 ano de idade, e pagava, ainda pagava sindicato. Agora, o meu rapaz (filho) aposentou-se com

\footnotetext{
${ }^{3}$ Instituto Nacional de Previdência Social (INPS) que hoje é o Instituto Nacional de Seguridade Social (INSS).
} 
45 ano. Mas ele veio novo, e já começou a trabalhar. Por isso que nos viemo pra cidade! (Ezequiel, 83 anos).

Esse trecho de sua fala demonstra que a aposentadoria significa a conquista de um direito e, influenciado pelas reivindicações do Sindicato dos Trabalhadores Rurais, questiona a idade mínima que era necessária para a conquista do benefício - 65 anos para os homens ${ }^{4}$. Ao longo de toda sua narrativa, a aposentadoria também aparece como elemento que arremata a construção da sua identidade como trabalhador, representando o reconhecimento da sua pertença ao trabalho na lavoura.

Ao comparar a idade de aposentadoria dos filhos com a sua, Ezequiel demarca as diferenças de oportunidade que existem entre a cidade e o campo, o que explica sua decisão de deixar a roça para viver na cidade. Ele queria dar uma vida melhor aos filhos. Mas a mudança só aconteceu depois da aposentadoria da esposa. Maristela era professora na comunidade rural em que moravam e depois de aposentada mudou com os filhos para a cidade: Me aposentei e dai vim embora pra cá. Eu me aposentei com 31 anos de serviço. Eu tava cansada já, dando graça de terminar logo (Maristela, 77 anos). Esse trecho da sua narrativa é muito interessante porque apresenta logo duas questões: a primeira é o sentido da aposentadoria como tempo de descanso, como recompensa pelo trabalho acabado. A segunda é que a aposentadoria representa a possibilidade de realizar um novo projeto, que no caso de Maristela é a mudança da família para a cidade. Nesse sentido, a aposentadoria significou o marco de uma vida melhor, a condição para recomeçar. Para ela, aposentadoria inaugura a possibilidade de parar de fazer para os outros, e passar a fazer para si (Maristela, 77 anos). Essa é a grande diferença que Maristela localiza na sua vida depois da aposentadoria.

Ana, que é agricultora aposentada, também aponta o lugar central que a aposentadoria toma em sua vida:

A gente melhorou depois que começou a receber, se não fosse isso, o que que era da vida da gente? Eu tive a pensão primeiro, depois eu me aposentei. A gente poder comprar o que queria. Depois que eu me aposentei que eu podia comprar as coisas. Que antes, o que que a gente tinha? A gente não tinha nada! Dai depois que me aposentei que comecei a comprar mais as coisa pra mim (Ana, 78 anos).

\footnotetext{
${ }^{4}$ Somente após a constituição de 1988, as mulheres passaram a ter direito ao benefício da aposentadoria rural. A idade mínima para o recebimento do benefício foi firmada em 60 anos para os homens e 55 anos para as mulheres. No caso da aposentadoria por idade dos trabalhadores urbanos, os homens precisam completar 65 anos e 15 de contribuição, já as mulheres precisam completar 60 anos e também apresentar contribuição de 15 anos.
} 
Ela demonstra que o significado do benefício previdenciário da aposentadoria rural é diretamente responsável pelos bens que consome e a qualidade de vida que conquistou atualmente. A aposentadoria está incorporada a sua condição de velha e, poderíamos dizer, reafirma na velhice sua história de trabalho como agricultora.

É Ana quem decide como o dinheiro da aposentadoria vai ser gasto: depois que me aposentei que comecei a comprar mais as coisa pra mim (Ana, 78 anos). Isso demonstra que além da melhoria da qualidade de vida gerada pela aquisição de bens materiais, como vestuário, eletrodomésticos e alimentação, a aposentadoria representa uma certa independência em relação aos filhos porque Ana tem seu próprio dinheiro e é ela que 0 administra. Esse significado particular que a aposentadoria rural assume na vida das mulheres, foi apontado no estudo de Heck e Langdon (2002) realizado com agricultores no interior do Rio Grande do Sul:

As mulheres, na atualidade, superam as relações com o espaço doméstico, de parentesco. Observamos que estão engajadas em grupos de discussão nos quais podem compartilhar informações, discutir problemas. Lentamente, despertam para uma auto-afirmação, descobrindo nesta a importância de se sentirem sujeitos com iniciativas e poder de decisão (HECK \& LANGDON, 2002, p. 142).

A velhice, no caso dessas mulheres, significa a possibilidade de extravasar do âmbito doméstico e participar também do espaço social. A pesquisa mostra que esse movimento acontece devido às mudanças sociais ocorridas com o direito ao recebimento da aposentadoria rural e a participação em grupos de idosos.

Outro sentido apresentado pelos nossos entrevistados é de que a velhice passa a ser encarada como uma etapa da vida em que a pessoa tem direito ao descanso. Ana afirma que só trabalha o necessário: 0 meu serviço é lavar louça, lidar aqui dentro de casa, mas a gente faz porque épreciso. Eu gosto mesmo é de passear, passear eu gosto (Ana, 78 anos). Essa questão aparece de forma mais intensa na narrativa de Estela, outra agricultora aposentada. Para ela, que trabalhou muito durante a vida muito mais de quarenta ano em serviço pesado, na roça (Estela, 95 anos), trabalhar significa preparar o terreno para alcançar uma boa velhice. Não há mais aquela obrigação de trabalhar como quando se é jovem, pois é direito que na velhice se possa descansar.

Essa noção que os entrevistados apresentaram sobre a aposentadoria como a conquista de um direito e como ponto positivo da velhice, deve-se em primeiro lugar ao fato de que a aposentadoria não significou uma ruptura abrupta com o mundo do trabalho. 0 trabalho não acaba com a aposentadoria, porque os aposentados encontram outras maneiras de utilizar seu tempo e de se sentirem úteis. Além disso, aposentar-se é o reconhecimento de uma condição social e de uma história ligada ao trabalho, que não 
seja somente o trabalho doméstico. Podemos nos indagar em que medida este reconhecimento não é para as mulheres um motivo de orgulho? E para os homens, como mostra Ezequiel, o reconhecimento social do pertencimento ao mundo do labor?

No caso da aposentaria rural, o benefício previdenciário no valor de um salário mínimo por mês representa uma significativa melhora na renda da família, que na maioria dos casos está acostumada a ter dinheiro apenas na época da safra. 0 agricultor, que recebia uma ou duas vezes por ano, através do benefício previdenciário da aposentadoria rural passa a contar com uma renda mensal facilitando a administração da renda. No caso das mulheres, o sentido do benefício previdenciário rural é ainda mais positivo, inclusive atuando como protagonista na identidade que elas constroem na velhice.

No contexto em que vivem os nossos entrevistados, a aposentadoria não significa necessariamente a ruptura com 0 trabalho. As narrativas apontaram para o fato de que 0 rompimento com 0 trabalho só acontece quando o idoso não tem mais condições físicas de realizar as tarefas às que estava acostumado, situação derivada da aparição ou agravamento de um problema de saúde e não da aposentadoria. Lourdes, aposentada como trabalhadora autônoma, conta que hoje em dia não pode mais trabalhar como antes por causa das dores que sente na coluna

E eu gosto de trabalhar, mas não posso forçar a coluna [...] Queria poder fazer as coisas. Só que agora olbo, mas não posso virar a terra, não posso plantar flor, eu gosto muito de flor. Eu, ano inteiro, sempre alguma flor no meu quintal tinha, mas agora tá tudo virado em mato. Parei por causa da coluna, por causa desse problema na coluna que eu não pude mais lidar na terra. (Lourdes, 78 anos).

Fica claro que foram as fortes dores na coluna que marcaram o fim da rotina de trabalho de uma vida inteira e não a aposentadoria, conquistada bem antes desse episódio.

Ezequiel, que depois de aposentado trabalhou ainda num sindicato, conta que quis sair [do sindicato] porque eu tenho uns problema, assim, dor nas juntas, dor no pé, e outra porque eu tinha pressão alta (Ezequiel, 83 anos). Também nesse caso, foi o mal-estar provocado pelas doenças que fizeram Ezequiel parar de trabalhar.

Professora aposentada aos 50 anos, Vitória fala sobre esse evento:

[E pra senhora, como foi se aposentar?]

É que eu continuei dando catequese, então tava sempre reunida com aluno, eu sempre na igreja eu tava, e tinha os alunos também que me queriam bem. Então não fiquei totalmente afastada. Eu fiquei afastada 
depois que eu tive problema de coração. Dai até a catequese eu abandonei. (Vitória, 79 anos).

A partir do que foi narrado por Vitória, é possível perceber o significado que a doença adquire na sua biografia que é o rompimento com o mundo do trabalho e a descontinuidade das práticas do cotidiano, muito mais que a aposentadoria.

Diante dos casos apresentados em que os velhos tiveram que parar de trabalhar, a doença apareceu como causa dessa condição. É o adoecimento que produz a ruptura não só com o trabalho, mas com a maioria das atividades rotineiras a que o velho está acostumado. Essas mudanças instauram um novo cenário na vida dos sujeitos, que os obriga a refletir e engendrar maneiras originais de lidar com a situação.

A continuidade do trabalho na velhice representa a luta para provar à sociedade seu lugar e marcar sua presença. A questão do trabalho é central na construção da identidade dos sujeitos e faz com que o velho sinta-se vivo e ativo. Sua ausência exige um processo de reconstrução dessa identidade e quando isso não ocorre faz com que 0 indivíduo se sinta um "peso morto". Nessa medida, a aposentadoria poderia ter significado a destituição dos seus papéis sociais, mas o que as narrativas tornaram visível foi que, no contexto da agricultura familiar e até mesmo dos trabalhadores urbanos, a aposentadoria não significa necessariamente 0 afastamento dos indivíduos das atividades laborais. Já que, em geral, os velhos substituem o trabalho por outras atividades que continuam garantindo seu lugar social.

A pesquisa de campo revelou ainda que, depois da aposentadoria, os velhos continuaram trabalhando nas mesmas atividades ou encontraram novas maneiras de ocupar seu tempo e sua mente: Sebastião saiu da construtora e passou a trabalhar como pedreiro por conta própria; Joaquim deixou de dirigir caminhão, mas continuou trabalhando na lavoura; o agricultor Ezequiel arranjou um emprego no Sindicato dos Trabalhadores Rurais e a professora Vitória continuou dando aulas para a turma da catequese. É pela realização dessas tarefas que 0 velho prova que o avanço da idade não retirou seu lugar no mundo, que continua vivo e atuante. No caso dos velhos que se aposentaram e continuaram realizando tarefas remuneradas, a aposentadoria significou ainda a possibilidade de aumentar o orçamento doméstico e gerar melhoria na condição de vida da família.

A aposentadoria também traz a possibilidade dos indivíduos instaurarem novas práticas cotidianas. Esse movimento apresenta a reconstituição do papel social do velho ou até mesmo a inauguração de um novo papel social, ligada às formas de sociabilidade proporcionadas nessa etapa da vida como o bingo e os grupos de terceira idade. 


\section{VELHICE PLURAL}

De fato, as narrativas sobre trabalho e aposentadoria comprovam que há variadas formas de envelhecer. Devido à infinidade de arranjos na trajetória biográfica dos velhos pesquisados, a velhice pode ser considerada uma experiência plural. A literatura sobre envelhecimento já havia atentado para esta pluralidade, entendendo a velhice como uma experiência social, marcada pela diversidade das trajetórias individuais.

A pluralidade das experiências sociais aponta para o fato de que também as imagens construídas sobre o envelhecimento sejam diversas e até mesmo discordantes, a velhice pode aparecer tanto como tempo de ganhos como também de perdas, o que demonstra quão plurais são também as experiências desses sujeitos.

Na contemporaneidade, a velhice foi construída na dicotomia jovem/velho, na que 0 velho é visto como decadente, feio e inativo. Visão esta, que levada às últimas consequências, significa que a velhice é considerada um peso para o restante da sociedade. No contexto brasileiro, essa imagem negativa dos velhos dominou soberana até as duas últimas décadas do século XX, e continua forte, devido ao discurso elaborado sobre a velhice na Geriatria, especialidade médica que inaugurou os estudos sobre velhice no país.

Mas, apesar da velhice conter uma ligação muito forte com a etariedade e com a finitude da vida, as narrativas coletadas na pesquisa de campo demonstraram que a velhice aparece ligada a vários fatores, sendo a idade um deles, mas não o mais importante, nem o único. 0 estudo de Ana Bassit (2002), com histórias de vida de velhas, confirma essa característica e afirma que "a idade cronológica por si só não é suficiente para explicar o envelhecimento, assim como é difícil precisar quando uma pessoa começa a envelhecer ou se torna um adulto" (BASSIT, 2002, p. 177).

As entrevistas realizadas em Mafra-SC também demonstraram que a velhice não tem data certa pra começar, e que ela só pode ser pensada se relacionada à condição do velho em relação ao exercício das atividades rotineiras, à possibilidade de movimentar-se e desenvolver algum trabalho, ou dependência com a necessidade de um cuidador. Essa questão demonstra que para compreendermos a velhice temos que olhar para as experiências de envelhecimento dos sujeitos.

Para Rabelo, Alves e Souza (1999, p. 11), problematizar a experiência significa assumir que a maneira como os indivíduos compreendem e se engajam ativamente nas situações em que se encontram ao longo de suas vidas não pode ser deduzida de um sistema coerente e ordenado de ideias, símbolos ou representações, já que "0 conhecimento através do qual se vive não é necessariamente o conhecimento através do qual se explica a vida". Essa condição pode ser evidenciada na pesquisa de campo com 
os velhos, que trouxeram a contradição entre a compreensão que eles têm da velhice e a forma que eles experimentam essa etapa de suas vidas. 0 caráter fluido e relativamente pouco estruturado do conhecimento é que permite ao estoque de conhecimento dar conta de experiências e acontecimentos que podem, a princípio, parecer contraditórios.

Essa questão foi evidenciada pela pesquisa de campo, que demonstra que a velhice não é somente um tempo de perdas - apesar de ser essa a visão predominante. As entrevistas trazem elementos para pensarmos a possibilidade de uma "outra" velhice, compreendida através das experiências vividas dos sujeitos, e não pelo discurso imposto na contemporaneidade sobre o que é ser velho. Essa outra velhice que se depreende de suas narrativas, possui uma concepção sutil sobre o que é ser velho, uma forma não pronunciada nas narrativas, mas que aparece na análise das experiências cotidianas e se localizam na contramão da imagem negativa historicamente construída em nossa sociedade.

A velhice como tempo de conquista toma formas variadas nas narrativas, mas em geral ela está ligada ao aumento do poder aquisitivo dos velhos, em especial daqueles que conquistaram o benefício previdenciário da aposentadoria rural (SUGAMOSTO, 2003). Mas a experiência dessa velhice mais positiva e alicerçada nas experiências individuais, também pode ser encontrada em outros temas, como os projetos para 0 futuro, a participação no grupo de terceira idade, atividades que preenchem o dia-a-dia dos velhos entrevistados e a comparação que eles fazem entre o passado e o hoje, tempo de velhice.

Vitória, por exemplo, vai realizar uma cirurgia para a retirada de catarata, ela diz que pinta e faz crochê tão bem quanto a neta, só precisa melhorar a vista. Para Vitória, a velhice aparece como continuidade das habilidades e gostos que cultivava desde jovem e, além disso, envelhecer não significa interromper o aprendizado de coisas novas:

Como ta ai essa pintura [pintura na toalha da mesa], isso dai tudo eu sei, e faço muito bem. Essas coisas aí foi a $\mathrm{L}$. [neta] que fez. Eu pinto igual ela e faço crochê, por isso que eu quero tratar da minha vista pra eu pintar melhor [...] E eu leio muito, ainda aprendo alguma coisa. Eu gosto, eu adoro ler. Por isso que eu vou trabalhar com a minha visão, que já ta me atrapalhando... (Vitória, 79 anos).

Dona Dolores, apesar da condição de abandono que relatou ao mudar para 0 asilo, descreve sua intensa participação no grupo de terceira idade durante anos: $E$ daí fui rainha do grupo de terceira idade de Rio Negrinho e fui aqui também, fui rainha da terceira idade, agora, ano passado (Dolores, 86 anos). Do ponto de vista da sexualidade, ela conta ainda que, recentemente, foi pedida em namoro: Com a idade 
que eu tenho, tudo, até tem um homem que veio, até me trouxe esse buquê de flor ali, ele queria namorar comigo (Dolores, 86 anos). A presença do desejo na velhice também aparece na fala de Joaquim: Eu gosto de andar bem vestido, isso dai faz parte, as mulher olham pra gente! (Joaquim, 74 anos). Nesses dois casos, o desejo despertado no outro significa a continuidade das performances sociais. 0 velho busca a continuidade das relações sociais, da interação com os outros indivíduos. Segundo Goffman (1983), o comportamento cotidiano na situação da interação é semelhante ao de atores no palco, sendo que os indivíduos e os grupos estão constantemente representando uns para os outros, tentando passar uma autoimagem positiva. Nessa perspectiva da comunicação social, o velho não quer ser visto como um indivíduo decadente e que não desperta interesse, por isso Joaquim se preocupa em cuidar do visual. E assim prossegue ocupando seu lugar de homem, de sujeito, atuando no espetáculo da vida.

Uma outra forma de vivenciar a velhice, conta Sebastião, é valorizar as situações cotidianas, pois viver bons momentos não significa ser jovem ou totalmente saudável, mas a alegria está nas pequenas coisas que cada um gosta de fazer: Alegria, se eu tiver lidando com terra, música ou pescaria, eu esqueço de comer (Sebastião, 83 anos). Se tiver fazendo o que gosta, os problemas desaparecem. Para Lourdes, chegar na velhice é uma vitória:

A bistória da vida da gente é a luta. Que a gente tem uma luta tão grande, tão pesada, que a gente sofreu bastante pra chegar nesse ponto, né. Agora que a gente tá aposentado, tá velhinho, tá mais melhor a vida do que aquela correria que a gente tava antes (Lourdes, 78 anos).

A comparação que estabelece entre a juventude e a velhice coloca esta última como tempo de conquista merecido, depois das dificuldades que enfrentou durante a vida. Para Carmem, a vida também teria melhorado à medida que foi ficando mais velha:

[A senhora gosta de morar sozinha?]

Eu gosto. Eu prefiro isolada do que no meio do povo. Eu gosto de ficar sozinha. A minha vida melhorou quando eu fiz mais idade, acho que em tudo. A gente não precisa mais trabalhar, trabalha quando quer. Sai quando quer e faz o que quer. Não como quando você tem a familia que você é obrigada a fazer as coisas. Melhorou em tudo (Carmem, 73 anos).

De certa forma, a imagem de uma velhice positiva também tem sido um discurso presente na sociedade contemporânea, através das expressões "velhice saudável" e da 
própria ideia de "terceira idade", como tempo de conquistas, prazer, lazer, entre outros. Contudo, a pesquisa de campo demonstrou que há ainda um discurso muito forte que coloca 0 velho como inativo, dependente e doente, sendo essa a visão que predominou nas narrativas quando os entrevistados falaram sobre a velhice. Haveria, portanto, uma dissonância entre o discurso sobre a velhice - essencialmente negativo, como símbolo da morte social do indivíduo - e a maneira que os velhos vivenciam suas práticas cotidianas. Diante dessa dissonância entre a experiência de envelhecimento e as representações sociais da velhice, destacamos que a velhice é uma experiência plural, e igualmente são as imagens construídas sobre ela. Essa constatação também foi verificada por Britto da Motta em seus estudos sobre a velhice e, segundo ela, estaríamos passando por uma transição na que a imagem social da velhice está melhorando, mas

(...) na realidade, ainda coexistem as duas imagens: a tradicional, "naturalizada", do velho inativo, respeitável mas inútil; e a nova imagem, mais dinâmica e participante, embora apenas em determinadas situações sociais (BRITTO DA MOTTA, 2002, p. 48).

Sobre essa convivência de olhares discordantes sobre a velhice, Minayo e Coimbra Jr (2002) chamam a atenção para a ambiguidade vivenciada pelo próprio indivíduo que envelhece, considerando que essa etapa da vida traz liberdade para 0 sujeito em relação à sua vida e, ao mesmo tempo, uma situação de dependência, enfrentada quando o corpo não se movimenta da mesma maneira que fazia antes. A velhice "é simultaneamente o tempo do orgasmo da vida e da liberdade e o tempo da medida do possível e da dependência. Tudo concomitante e tudo diferenciado pela trajetória individual" (MINAYO \& COIMBRA JR, 2002, p.13).

De um modo geral, a pesquisa procurou demonstrar que não há uma maneira única de vivenciar o envelhecimento, pois várias são as velhices possíveis. Estas são constituídas tanto pelo tempo histórico-social do qual fazem parte, como também pelas trajetórias individuais, que marcam sobremaneira a subjetividade das experiências de envelhecimento.

\section{REFERÊNCIAS}

BASSIT, Ana. Z. Histórias de mulheres: reflexões sobre a maturidade e a velhice. In: MINAYO, Maria Cecília \& COIMBRA Jr, Carlos E. A. (orgs.) Antropologia, Saúde e Envelhecimento. Rio de Janeiro: Fiocruz, 2002.

BOSI, Eclea. Memória e Sociedade: Lembranças de velhos. São Paulo: Companhia das Letras, 1994. 
BRITT0 DA MOTTA, Alda. Envelhecimento e sentimento do corpo. In: MINAYO, Maria Cecília \& COIMBRA Jr, Carlos E. A. (orgs.) Antropologia, Saúde e Envelhecimento. Rio de Janeiro: Fiocruz, 2002.

DEBERT, Guita G. \& GOLDSTEIN, Donna M. (orgs.) Políticas do corpo e o curso da vida. São Paulo: Sumaré, 2000.

DELGADO, Josimara. Velhice, corpo e narrativa. Horizontes Antropológicos. Porto Alegre, ano 16, n. 34, p . 189-212, jul/dez 2010.

GOFFMAN, Erving. A representação do eu na vida cotidiana. Petropolis: Vozes, 1983.

HECK, Rita M. \& LANGDON, Esther J. M. Envelhecimento, relações de gênero e o papel das mulheres na organização da vida em uma comunidade rural. In: MINAYO, M. C. \& COIMBRA JR, C. E. A. (orgs.) Antropologia, Saúde e Envelhecimento. Rio de Janeiro: Fiocruz, 2002.

MINAYO, Maria Cecília \& COIMBRA Jr, Carlos E. A. (orgs.) Antropologia, Saúde e Envelhecimento. Rio de Janeiro: Fiocruz, 2002.

PEIXOTO, Clarice. Entre o estigma e a compaixão e os termos classificatórios: velho, velhote, idoso, terceira idade... In: BARROS, Myriam L. (org) Velhice ou terceira idade?: Estudos antropológicos sobre identidade, memória e política. Rio de Janeiro: Fundação Getúlio Vargas, 1998.

RABELO, Miriam; ALVES, Paulo \& SOUZA, Iara. Experiência de doença e narrativa. Rio de Janeiro: Fiocruz, 1999.

SCHUTZ, Alfred. Fenomenologia das relações sociais. Rio de Janeiro: Zahar, 1979.

SUGAMOSTO, Marisa Velhice e beneficio previdenciário entre os agricultores familiares do município de Colombo - Paraná. Dissertação de Mestrado, Sociologia, Setor de Ciências Humanas, Letras e Artes, Universidade Federal do Paraná, Curitiba, 2003. 